\title{
Breast Cancer Surgery - Oncological Aspects
}

\author{
Ulrike Nitz $^{a^{*}}$ Regina Grosse ${ }^{b}$ Christoph Thomssen ${ }^{\text {b* }}$ \\ a Universitäts-Frauenklinik Düsseldorf,

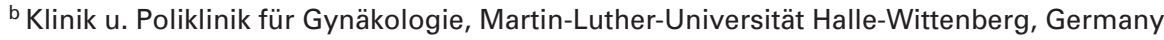

\section{Key Words}

Diagnostics, preoperative $\cdot$ Core-needle biopsy .

Staging - Breast conserving therapy .

Sentinel lymph node excision

\section{Summary}

Preoperative clinical examination, mammography, ultrasound and, in selected cases, magnetic resonance imaging provide information about TN status, tumor localization and a potential intraductal component. Diagnosis should be confirmed by preoperative core-needle biopsy histology, grading, hormone receptor status, and HER2/neu expression etc. in order to estimate risk of recurrence and treatment efficacy. If systemic risk is high, preoperative staging with bone scintigraphy, chest X-ray and abdominal ultrasound or CT identify patients with metastatic disease, who will not necessarily benefit from radical surgery. Most patients with T1-tumors are candidates for breast conserving surgery (BCT), which, in combination with radiotherapy of the breast, is as safe as mastectomy. Margins should be free of tumor. Only multicentric disease, inflammatory breast cancer and unfavorable tumor versus breast volume are contraindications for BCT. Plastic surgery often allows resection of large tissue volumes with good cosmesis and minimal scars and may help to avoid mastectomy in many cases. Concerning axillary surgery, the resection of at least 10 lymph nodes has been considered standard. Axillary surgery is responsible for the majority of postoperative morbidity. In very small tumors and in the elderly with clinically negative axillae and small tumors there is some evidence that omitting axillary surgery may not reduce survival rates. In clinically node-negative patients with unifocal tumors not exceeding $5 \mathrm{~cm}$ sentinel lymph node excision is widely accepted although long-term survival data are still lacking. Multicentricity, inflammatory disease and extensive prior breast surgery and prior surgery of the axilla are contraindications for sentinel lymph node excision.

*As members of the Breast Commission, part of the AGO (Working Group Gynecologic Oncology, German Society of Obstetrics and Gynecology)

\author{
Schlüsselwörter \\ Diagnostik, präoperative $\cdot$ Nadelbiopsie . \\ Metastasenscreening - Operation, brusterhaltende . \\ Wächterlymphknotenentfernung
}

\section{Zusammenfassung}

Die komplette Diagnostik mit klinischer Untersuchung, Mammographie, Ultraschall und in ausgesuchten Fällen mit Kernspintomographie erlaubt bereits präoperativ eine präzise Aussage über den TNStatus und eine potentielle intraduktale Tumorkomponente. Bei Diagnosestellung mittels Nadelbiopsie liegen mit der Histologie, dem Grading, mit dem Hormonrezeptorstatus und der HER2/neu-Expression weitere Faktoren vor, die eine Abschätzung des Rezidivrisikos und des Therapieeffekts erlauben. In Fällen mit hohem Metastasenrisiko sollten durch präoperatives apparatives Staging Patientinnen, die wegen Fernmetastasen nicht von einem radikalen chirurgischem Vorgehen profitieren, identifiziert werden. Die meisten Patientinnen mit T1-Tumoren sind Kandidatinnen für eine brusterhaltende Therapie. In Kombination mit der Bestrahlung der Brust ist sie der Mastektomie gleichwertig. Kontraindikationen sind multizentrisches Tumorwachstum, inflammatorisches Mammakarzinom und ggf. ein ungünstiges Brust/Tumorverhältnis. Hier haben plastisch chirurgische Verfahren bei Resektion großer Gewebevolumina die Anzahl der Patientinnen, die mit gutem kosmetischen Ergebnis brusterhaltend operabel sind, erheblich steigern können. In Hinblick auf die Axilla ist die Entfernung von 10 Lymphknoten Standard. Sie ist für einen Großteil der postoperativen Morbidität verantwortlich. Bei sehr kleinen Tumoren und bei älteren Patientinnen mit klinisch unauffälliger Axilla und kleinen Tumoren kann in Einzelfällen auf die Operation der Axilla verzichtet werden. Bei Patientinnen mit unifokalen Tumoren $<5 \mathrm{~cm}$ und klinisch und sonographisch freier Axilla ist die Wächterlymphknotenentfernung (Sentinel-Exzision) trotz fehlender Langzeitdaten als Standard akzeptiert. Als Kontraindikationen gelten ausgedehnte Voroperationen im Bereich der Brust oder der Axilla sowie multizentrisches und inflammatorisches Mammakarzinom.

\begin{tabular}{ll}
\hline KARGER & ๑ 2006 S. Karger GmbH, Freiburg \\
Fax +49 761 4520714 & Accessible online at: \\
$\begin{array}{l}\text { E-mail Information@Karger.de } \\
\text { www.karger.com }\end{array}$ & www.karger.com/brc
\end{tabular}

Prof. Dr. med. Christoph Thomssen Brustzentrum Halle, Klinik u. Poliklinik für Gynäkologie Martin-Luther-Universität Halle-Wittenberg Ernst-Grube-Str. 40, 06097 Halle/Saale, Germany Tel. +49 345 557-1847, Fax -1501

E-mail christoph.thomssen@medizin.uni-halle.de 


\section{The Role of Surgery}

Until the beginning of the 1970s, locoregional surgery, later in combination with radiotherapy, was the only treatment option for breast cancer. Although prospective trials were performed in order to show that breast-conserving therapy is feasible without disadvantage with regard to overall survival, the precise value of surgery within a multimodal treatment strategy of breast cancer has never been evaluated in a prospective randomized trial. Peto et al. [1] performed a retrospective analysis using the risk reduction of local recurrence as a surrogate marker for adequate surgery by comparing the following categories: less than $10 \%$, between 10 and $20 \%$, and more than $20 \%$ gain of local control. Within the first 4 years, the annual breast cancer related death rates for each group did not differ significantly. After 5 years, the mortality correlated significantly with the magnitude of local control gain $(p=0.00005)$. These data suggest that trials aimed at the evaluation of different surgical strategies should focus on long term survival, since early breast cancer deaths seem only marginally affected by effective local control.

\section{Preoperative Diagnosis}

The role of open biopsy in the diagnosis of breast cancer has been challenged. Current guidelines recommend core needle biopsy as standard procedure for diagnosing palpable lumps as well as non-palpable sonographic and mammographic lesions [2], although the advantage of this procedure has never been formally (peer-reviewed) proven. At the San Antonio Breast Cancer Symposium 2005, Edge et al. [3] presented data from the National Comprehensive Cancer Network. Among 6,282 breast cancer patients, 57\% were diagnosed by core needle biopsy and $43 \%$ by open surgery. Re-excision was significantly associated with the type of initial biopsy $(23 \%$ core needle vs. $92 \%$ surgery). Mean time to complete surgery was 30 days without re-excision and 48 days with re-excision. Far beyond the reported data, the widespread availability of true cut or core needle biopsy provides surgeons with an important tool for intelligent preoperative planning. Surgery should no longer play a major role in the diagnosis of breast cancer. Diagnosis prior to surgery enables the surgeon to discuss and to plan with the patient the best surgical approach in terms of breast conservation, mastectomy (with or without reconstruction), sentinel lymph node biopsy etc. on the basis of a clear diagnosis. Beside histological examination of core needle biopsy specimens (true cut or vacuum assisted), AGO (Arbeitsgemeinschaft Gynäkologische Onkologie) experts recommend clinical examination, adequate mammography and sonography of the breasts and the axillae as preoperative routine diagnostic procedures.

Magnetic resonance imaging (MRI) may be a valuable instrument for detection of small tumors and multifocal/multicen-

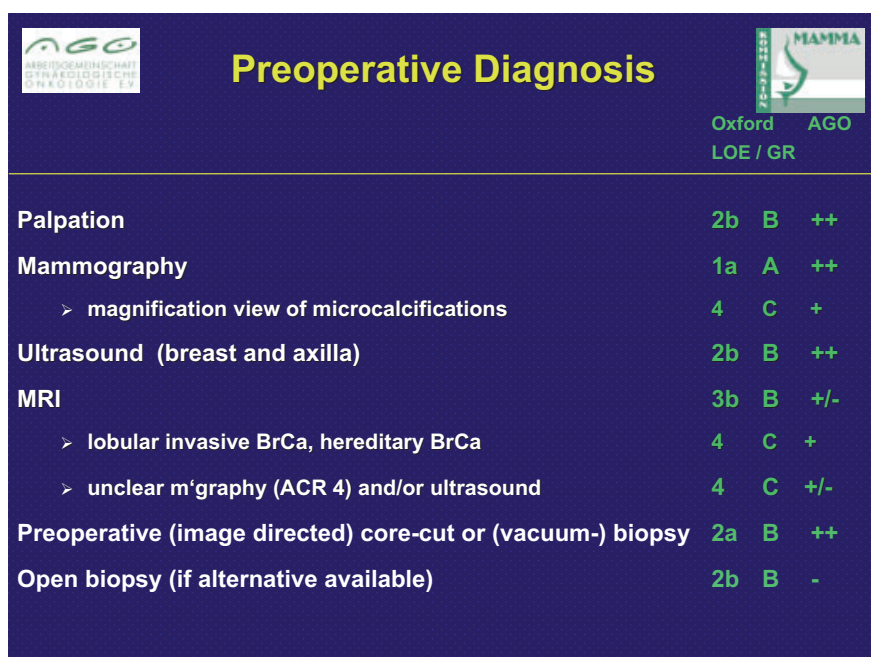

Fig. 1. Preoperative diagnostic procedures.

tric disease. Important additional preoperative information may be gained particularly in cases of radiographically dense breast tissue (ACR 4) and histologically confirmed lobular carcinoma with a high rate of multifocality and contralateral disease. MRI should also be performed preoperatively in patients with hereditary breast cancer. However, due to the lack of standardization and particularly due to the heterogenous data pertaining to specificity, MRI is not yet recommended as a standard preoperative diagnostic procedure outside of clinical trials. Figure 1 summarizes the recommendation for preoperative diagnosis of the breast.

\section{Preoperative Staging}

As summarized in figure 2, preoperative personal medical history and clinical examination are mandatory. Staging involving chest X-ray, liver sonography, CT (computed tomography) scan and bone scan are recommended in symptomatic patients. In asymptomatic patients, pathological findings of these routine staging procedures will be found more frequently in advanced stages of disease. In 2003, the American Joint Committee on Cancer Staging reported on 1,939 asymptomatic breast cancer patients who received routine bone scans. Pathological findings were reported in only $0.7 \%$ of stage I but in $10.5 \%$ of stage III b patients [4]. The ESMO (European Society for Medical Oncology) guidelines recommend imaging for screening of metastases only in patients with higher risk $(\mathrm{N} 2,>/=4$ positive axillary nodes, $\mathrm{T} 4)$ and in patients with clinical or laboratory findings that are suspicious of metastatic disease [5]. However, since diagnosis of metastatic disease changes the treatment strategy dramatically, complete preoperative staging should be generously considered.

To date, preoperative treatment planning can be based on staging, results of diagnostic procedures and histology. Clinical examination, mammography and ultrasound give a good 


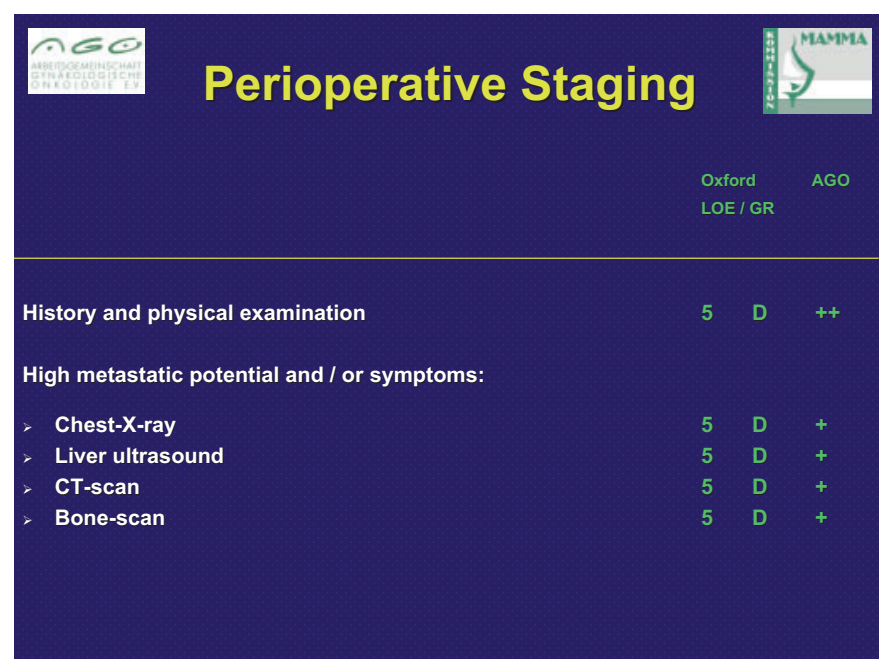

Fig. 2. Preoperative staging.

approximation of tumor size, multifocality and multicentricity. Clinical examination and ultrasound, especially when accompanied by fine needle aspiration cytology, may identify axillary lymph node involvement. Mammographically detected microcalcifications and histology of needle biopsies may provide information about an intraductal component. Needle biopsies enable histological diagnosis of malignancy, and most pathologists will assess the grade of differentiation and perform immunohistochemistry for assessment of the steroid hormone receptor status and HER2/neu overexpression on material from needle biopsies. Together with age and family history, this allows a good preoperative assumption of the potential risk of local recurrence and, in consequence, the choice of resection volume. Furthermore, the surgeon will obtain valuable information concerning systemic risk and the role of local control for each individual patient.

\section{Breast-Conserving Surgery - Mastectomy}

In Germany, at least $60 \%$ of patients will have breast-conserving surgery and subsequent radiotherapy of the breast. 20-year results from large prospective randomized trials have confirmed that survival data in these cases are equivalent to those reported after modified radical mastectomy [6, 7].

\section{Technical Aspects of Breast-Conserving Surgery - General Recommendations}

In non-palpable lesions, a guide-wire should be inserted into the suspicious lesion, assisted by mammography, sonography or MRI (depending on the method by which the lesion can best be detected), and a wire-guided excision should be performed. Control of the resected tissue (adequately orientated to allow re-excision in case of close margins) should be done intraoperatively utilizing the same method (ultrasound or specimen radiography) in order to ensure that the target vol- ume has been resected. Tumor excision should be performed in accordance with the anatomy of the breast (resection of ductal segments, due to potential intraductal tumor spread). In subdermal tumors, skin resection should be performed respecting the individual anatomy (dermal pattern, orientation parallel to the areola).

For optimal planning of boost irradiation (generally patients $<50$ years old), the tumor bed should be marked by a titanium clip, particularly in the case of internal glandular flap reconstruction. It is standard and strongly recommended to achieve tumor-free margins confirmed by pathohistological examination of paraffin-embedded material. If postoperative histological assessment detects incomplete resection, re-excision should be performed. The question of margins in invasive breast cancer is much less well defined than for ductal carcinoma in situ (DCIS). In the case of pure DCIS, local control means cure in the vast majority of cases. The same is not true for invasive breast cancer due to the systemic character of the disease. The panel of AGO experts could not come to a consensus concerning tumor-free width in millimeters ('multiple publications for each mm'). However, all AGO experts agree that at least the specimen margins must be free of tumor.

Prior to the operation, the surgeon should be aware of the individual risk of local recurrence, the individual risk of systemic recurrence, and the individual anatomy. The patient's preference concerning the method of operation should also be respected. Breast conserving therapy should not be performed in cases of multicentricity, involved margins after repeated re-excision and inflammatory breast cancer. Relative contraindications are unfavorable ratio of tumor to breast volume, central tumor location, extensive intraductal component and cases in which radiotherapy is not feasible (e.g. prior radiotherapy), as well as other situations that may cause unfavorable cosmetic results (e.g. microangiopathia due to diabetes, sclerodermia, adiposomastia, macromastia).

\section{Technical Aspects of Mastectomy - General Recommendations}

Large prospective randomized trials conducted in the last century reported survival rates after modified radical mastectomy that were equivalent to those after radical mastectomy (level of evidence (LoE) 1b, grade of recommendation A, $\mathrm{AGO}++)[8,9]$. If possible, even with modified radical mastectomy the inframammary fold and the décolleté should be preserved for later reconstruction.

Large retrospective trials have demonstrated that skin-sparing mastectomy respecting the topography of the tumor does not result in inappropriate local recurrence rates ( $\mathrm{LoE} 2 \mathrm{~b}$, grade of recommendation $\mathrm{B}, \mathrm{AGO}++)$. Smaller retrospective series have shown that even skin-sparing mastectomy with preservation of the nipple-areola complex in the case of tumors located in the periphery of the breast may represent a safe procedure ( $\mathrm{LoE} 4 \mathrm{~b}$, grade of recommendation $\mathrm{C}$, $\mathrm{AGO}+)[10]$. 


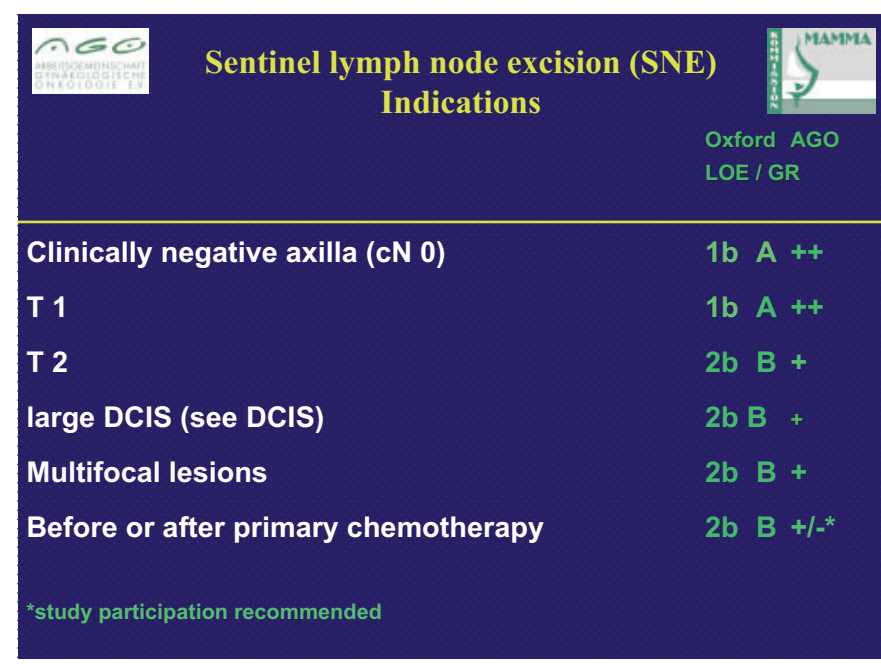

Fig. 3. Indications for sentinel lymph node excision (SNE).

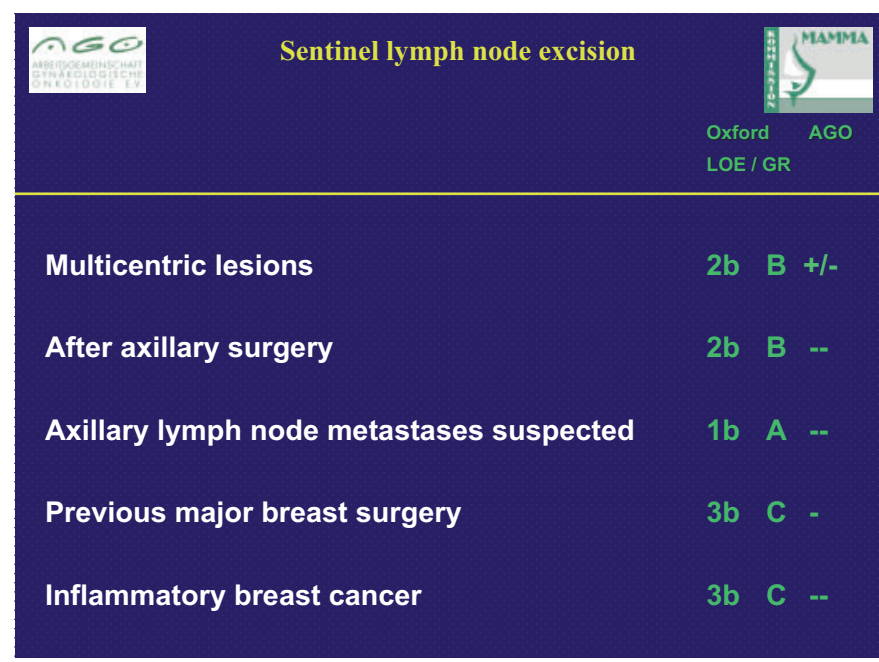

Fig. 4. Contraindications for sentinel lymph node excision (SNE).

Table 1. Frequently asked questions and possible answers

Q: Should immunohistochemical evaluation of sentinel lymph node excisions (SNE) be used?

A: The relevance of immunohistochemical evaluation of SLN is unclear [15].

Q: Is axillary lymph node dissection necessary if isolated tumor cells are detected in the sentinel lymph node (SLN)?

A: In these cases, rates of macro- $(1.6 \%)$ and micrometastases $(3.3 \%)$ in non-SLN were found to be low $(n=61)$ [16].

Q: SLN histology N0(i+) vs. N1mi $(0.2-2 \mathrm{~mm})$ - Is there a correlation with survival?

A: Patients with N0(i+) show a significantly better prognosis than N1mi [17].

Q: Does a clinically positive axilla $(\mathrm{cN}+)$ represent a contraindication for $\mathrm{SNE}$ ?

A: According to a report of $106 \mathrm{SNE}$ in $\mathrm{cN}+$ patients, clinical examination was false-positive in $53 \%$; the authors recommend other means of preoperative assessment, e.g. ultrasound-guided fine needle aspiration [18].

Q: In which cN0 cases should primary axillary dissection be performed (without prior SNE)?

A: In $726 \mathrm{cN} 0$ patients who underwent ultrasound and fine needle aspiration when the cortex of the lymph node detected by ultrasound was larger than $2.3 \mathrm{~mm}, 8 \%$ of SLN were avoided because patients were identified to be $\mathrm{pN}+$ [19].

Q: Is axillary radiotherapy an alternative to axillary dissection in SLN+ patients?

A: One paper reports on axillary irradiation in $73 \mathrm{pNsn}+$ patients with a median follow-up of 32 months. One axillary relapse and one transient arm edema were observed [20].

Q: Does tumor-infiltrated SLN necessitate subsequent axillary lymph node dissection?

A: Yes [21].

Q: Should SNE be performed after primary chemotherapy?

A: Although large series show detection and false-negative rates comparable to chemotherapy-naïve patients, a recently published meta-analysis summarizes a false-negative rate of $12 \%[22,23]$.

\section{Axillary Surgery}

The removal of at least 10 axillary lymph nodes is still the standard of axillary surgery. In patients with pathologically confirmed node-negative disease, axillary surgery must be considered a staging procedure that identifies patients at lower risk of recurrence. In the case of tumor infiltrated axillary lymph nodes, the procedure has both a diagnostic and therapeutic goal. Since the axillary component of breast cancer surgery is responsible for the majority of postoperative morbidity (paresthesia, pain, impaired mobility of the shoulder/arm, and even lymphedema,), tremendous effort has been exerted in recent years to identify those patients who may not benefit from axillary dissection because of node-negative status. Sentinel lymph node excision (SNE) in clinically negative breast cancer patients is an alternative to conventional axillary surgery and may safely predict axillary lymph node involvement. Although long-term survival data from the prospective randomized trials comparing SNE with conventional axillary surgery have not yet been published, the procedure is widely accepted. A summary of technical aspects and patient selection reflecting the German consensus has been published [11].

Recent reports on long-term morbidity confirm the significant reduction of postoperative morbidity of the arm and shoulder $[12,13]$. In addition, a meta-analysis by Kim et al. [14] of about 70 publications shows that even in small case series, the 
false-negative rate in SNE rarely exceeds $10 \%$ (in summary 230/3,121 = 7\%). Clinically, the sentinel lymph node detection rate is the best surrogate parameter for the false-negative rate. Many questions concerning SNE, including optimal fol- low-up, remain unanswered. Indications for SNE are listed in figure 3 and contraindications in figure 4. Table 1 summarizes some of the most frequently asked questions and the corresponding recent publications.

\section{References}

1 Peto R: Oral presentation SABC 2004.

2 Rutgers EJ: Quality control in the locoregional treatment of breast cancer. EUSOMA Consensus Group. Eur J Cancer 2001;37:447-53.

3 Edge SB, Ottesen RA, Lepist EM, et al.: Surgical biopsy to diagnose breast cancer adversely affects outcomes of breast cancer care: finding from the National Comprehensive Cancer Network. SABCS 2005; abstr 12.

4 Park SS, Han W, et al.: The clinical use of staging bone scan in patients with breast cancer. Cancer 2005;104:499-503.

5 Pestalozzi BC, Luporsi-Gely E, Jost LM, Bergh J; ESMO Guidelines Task Force: ESMO minimum clinical recommendations for diagnosis, adjuvan treatment and follow-up of primary breast cancer. Ann Oncol 2005;16(suppl 1):i7-i9.

-6 Fisher B, Anderson S, Bryant J, Margolese RG, Deutsch M, Fisher ER, Jeong JH, Wolmark N: Twenty-year follow-up of a randomized trial comparing total mastectomy, lumpectomy, and lumpectomy plus irradiation for the treatment of invasive breast cancer. N Engl J Med 2002;347:1233-41.

7 Veronesi U, Cascinelli N, Mariani L, Greco M, Saccozzi R, Luini A, Aguilar M, Marubini E: Twentyyear follow-up of a randomized study comparing breast-conserving surgery with radical mastectomy for early breast cancer. N Engl J Med. 2002;347: 1227-32.

8 Oxford Levels of Evidence 2001 www.cebm.net/levels_of_evidence.asp.

9 AGO Guidelines Breast Cancer 2006. www.ago-online.de.

10 Hanf V, Audretsch W: Operatives Vorgehen unter plastisch/rekonstruktiven Aspekten; in von Minckwitz GW (ed): Aktuelle Empfehlungen zur Therapie primärer und fortgeschrittener Mammakarzinome. München, Zuckschwerdt, 2005.
11 Kuehn T, Bembenek A, Decker T, Munz DL, Sautter-Bihl M-L, Untch M, Wallwiener D, for the Consensus Committee of the German Society of Senology: A concept for the clinical implementation of sentinel lymph node biopsy in patients with breast carcinoma with special regard to quality assurance. Cancer 2005;103:451-461.

12 Fleissig A, Fallowfield LJ, Langridge CI, et al.: Postoperative arm morbidity and quality of life. Results of the ALMANAC randomized trial comparing sentinel lymph node biopsy with standard axillary treatment in the management of patients in early breast cancer. Breast Cancer Res Treat 2006; 95:279-93.

13 Purushotham AD, Upponi S, Klevesath MB et al.: Morbidity after sentinel lymph node biopsy in primary breast cancer: result from a randomized controlled trial. J Clin Oncol 2005;23:4312-21.

14 Kim T, Guiliano AE, Lyman G: Lymphatic mapping and sentinel lymph node biopsy in early stage breast carcinoma. Cancer 2006;106:4-16.

15 Lyman GH, Giuliano AE, Somerfield MR, et al.: American Society of Clinical Oncology guideline recommendations for sentinel lymph node biopsy in early-stage breast cancer. J Clin Oncol 2005;23: 7703-20.

16 Calhoun KE, Hansen NM, Turner RR, et al.: Nonsentinel node metastases in breast cancer patients with isolated tumor cells in the sentinel node: implications for completion axillary node dissection. Am J Surg 2005;190:588-91.

17 Cox C, Vrcel V, Riker A, White L, Allred N, Ramos D, Myers M, Dupont E, King J, Cantor A, Diaz N: Significance of sentinel lymph node micrometastasis on survival for patients with invasive breast cancer. SABCS 2005:abstr 21.
8 Specht MC, Fey JV, Borgen PI, Cody HS 3rd: Is the clinically positive axilla in breast cancer really a contraindication to sentinel lymph node biopsy? Am Coll Surg 2005;200:10-4.

19 Van Rijk MC, Deurloo EE, Nieweg OE, Gilhuijs KGA, Peterse JL, Rutgers EJT, Kröger R, Kroon BBR: Ultrasonography and Fine-Needle Aspiration Cytology Can Spare Breast Cancer Patients Unnecessary Sentinel Lymph Node Biopsy. Ann Surg Oncol 2006;13:31-35.

20 Gadd M, Harris J, Taghian A, Hughes K, O’Neil A, Powell S, Christian R, Lesnikoski B, Kaelin C, Rhei E, Iglehart J, Habin K, Oberg J, Younger J, Winer E, Smith B: Prospective study of axillary radiation without axillary dissection for breast cancer patients with a positive sentinel node. SABCS 2005: abstr 22 .

21 Julian TB, Anderson S, Brown A, Krag D, Harlow S, Bear H, Ashikaga T, Weaver D, Miller B, Jalovec L, Frazier T, Noyes RD, Robidoux A, Scarth H, Mammolito D, McCready D, Mamounas E, Costantino J, Wolmark N: Continued technical results of NSABP B-32: Does a positive sentinel node biopsy require an axillary dissection? SABCS 2005: abstr 20.

22 Mamounas EP, Brown A, Anderson S, et al.: Sentinel lymph node biopsy after neoadjuvant chemotherapy in breast cancer: results from National Surgical Adjuvant Breast and Bowel Project Protocol B-27. J Clin Oncol 2005;23:2694-702.

23 Xing Y, Foy M, Cox DD, et al.: Metaanalysis of sentinel lymph node biopsy after preoperative chemotherapy in patients with breast cancer. Br J Surg 2006;93:539-46. 